\title{
DEVELOPMENT OF DIVERSITY COMPETENCY IN HEALTH PROFESSIONALS: PRELIMINARY INVESTIGATION
}

\author{
Valencia $\mathrm{J}^{*}$, Turrubiates $\mathrm{M}$ and Olivares $\mathrm{S}$ \\ Tecnologico de Monterrey, Escuela de Medicina y Ciencias de la Salud, Mexico
}

\begin{abstract}
Migratory displacements, the multiplicity of ethnic groups, and tremendous cultural diversity in today's society (culture, sex, religion, language, education, sexual orientation) worldwide have made it necessary for health professionals to address the immediate demands and needs of society. The objective of this study was to identify the development of diversity competency through educational innovations. The methodology was quantitative, descriptive, and cross-sectional. The tool was a questionnaire used as a pre-test and post-test to measure the value perceived by the students participating in our university's Tec Week activities. It was applied to the total number of students enrolled in the Tec Week activities. The questionnaire was answered by 21 students participating in the activities "Me, You, Others, Us" and "Diversity in a Globalized World." Focus groups validated the questionnaire; for statistical analysis, the Wilcoxon test was used and Cronbach's Alpha (0.97). The results of the Tec Week activities "Me, You, Others, Us" and "Diversity in a Globalized World" showed the dimension in which students feel more confident in their self-reflection. For the diversity competency, it was "Strengthen my Support for Gender Equality." However, the activity in which the students did not feel confident in both the pre and post-tests was "Participate in Inclusion Initiatives with Vulnerable Groups." The development of diversity competency contributes high value to the training of health professionals. It is based on human rights and individuality and considers the patient's characteristics, expressing openness, interest, and disposition towards the diversity surrounding them.
\end{abstract}

Keywords: Generic competencies, diversity competency, health professionals, higher education, educational innovation

\section{Introduction}

The higher education institutions that offer health careers are challenged to train professionals as experts in their disciplines with up-to-date knowledge and develop competencies that prepare them to adapt to professional and personal environments in the future.

In the health field, students must develop skills for professional life such as diversity competency because, during their professional careers, they will encounter patients with unique health situations related to the disease. Beyond this, they must have sensitivity to social differences to increase the patients' access and treatment appropriation to positively impact their health (Sias et al., 2017).

Among the main challenges that future health professionals will face in Mexico is population diversity: $6.4 \%$ of the population speaks an indigenous language. The migratory flow from the south to the north is more than 400,000 people annually, mainly Central Americans seeking family 
reunification, fleeing violence, or looking for better economic conditions (UN, 2017). The percentage of the LGBT community in 2017 was $1.9 \%$, while $16.5 \%$ of the population had a disability (INEGI, 2017; INEGI, 2020). These facts necessitate that schools of medicine and health sciences establish the facilities, programs, and protocols to develop students who are open, empathetic, and tolerant to the great diversity in society. They must have a sense of self and sensitivity to others (Vinasco, 2018) and are prepared to take on the complex needs of the problems that afflict society.

This behavior of knowing and recognizing the diversity of the environment must be embraced and nurtured by educational institutions to better train health professionals. To do so, new learning environments and curricular approaches must focus on generic skills. In health-professions education, these competencies are crucial as students need to understand the cultural and ethnic diversity of the patients they attend for in truly patient-centered care.

\section{Generic skills}

Competency is understood as the ability of a person to effectively perform with the knowledge, skills, values, and attitudes to tackle complex tasks (Pugh \& Lozano, 2020). Competencies are classified as specific and generic; the former refers to those of a profession or occupation. The latter, also known as transversal or soft skills, refers to those required for employment in different professions and life. These skills are critical for university students to tackle their future responsibilities as citizens and professionals (Crespi \& García, 2020; Salgado et al., 2012).

The training in generic competencies is indispensable in the adequate training of university students for their roles in society. The mission of higher education institutions is to provide comprehensive and humanistic training that puts students on the path of personal and professional responsibility. Thus, generic competency development should be a goal of training, not a corollary in achieving specific skills.

Comprehensive training of health professionals enriches the educational process, as the students become professionals in the broadest meaning of the word. An education aimed at comprehensive training considers the person as a whole being, recognizing multiple human dimensions not as discrete parts but in constant interrelations. Students under permanent construction fully participate in life as they become lifelong learners preparing for complex environments and unlimited possibilities (Morales, 2009; Olivares, 2015).

Thus, the appropriation of diversity competency in spaces designed for its development promotes the ability to apply what has been learned in clinical and non-clinical contexts, considering that learning is not achieved independently. It requires constant guidance or orientation to attain educational objectives, so new formative assessment and reflection scenarios must be available to ensure that the student develops the necessary generic competencies to succeed in daily life.

Diversity competency in the training of health professionals

According to Sweetman (2004), diversity can be seen from two dimensions, the primary and the secondary. The primary has to do with those characteristics that a person cannot change, such as age, race or ethnicity, and sex. The secondary dimension refers to characteristics that can change, such as 
nationality, religion, marital status, residence, and sexual orientation. The General Act on Equal Treatment (2006) describes diversity in six categories: age, gender, ethnicity, physical disability, sexual orientation, and religion, but it also includes other aspects having to do with inclusion and discrimination, such as socioeconomic status, educational level, and physical appearances. These different characteristics of diversity must be considered in health care. Another important source of diversity has emerged from refugee migration resulting from foreign policies and major global crises. As a result, diversity has increased within society. Thus, in all applications of care, health professionals need to attend to patients with different needs and characteristics, such as religion, sexual orientation, disabilities, or gender.

The development of diversity competency in health professionals helps address growing inequalities at both the epidemiological and social levels. They need to establish effective communication strategies, respect, empathy, ethics, and professionalism. However, most of these transversal skills are only implicit in the curriculum of undergraduate programs in health sciences. The lack of these competencies in the formal curriculum translates to graduating students who are not always prepared to perform in complex settings. Seeleman et al. (2015) argue that in most cases, students and even physicians do not have diversity knowledge and competency nor culturally competent behavior, which would allow them to focus relevant attention on the patient. This is because there has been no attention to the patient's needs, not only their illness but also their holistic needs, including social, political, economic, and health problems. This must come from public policies that guarantee patientcentered care.

To ensure comprehensive medical care, medical schools must include different components of diversity in the curriculum and training of health professionals, considering their attitudes and professional skills (Shaya \& Gbarayor, 2006). By turning their gaze to diversity, health institutions, professionals, and teachers guide the transformation of patient care and health services; diversity becomes a key feature in the quality and standards of care (López, 2016). Suarez et al. (2014) mention that medical personnel and other health professionals training in diversity must be able to promote:

- a multicultural mission based on values of equality and diversity;

- reciprocal relationships with stakeholders in decision-making processes;

- the ability to participate in new roles;

- leadership capable of representing equally the needs and points of view of all participating actors.

The development of diversity competency in health professionals emphasizes the importance of human rights, individuality, and caring for every patient's uniqueness. The professionals' care expresses openness, interest, and appreciation for the diversity surrounding them, so it is necessary to expose students in the health area to contextual experiences and learning spaces that facilitate the use and application of diversity competency.

Thus, the bibliographic review performed throughout this study allows an overview of the development of diversity competency in health professionals. In the reviewed studies, the predominant orientation to diversity focuses on those characteristics that the person may or may not change. However, it does not emphasize what is being done in the healthcare training of students for diversity, leaving a gap in this critical and relevant competency of future health professionals. 


\section{Diversity competency at Tecnologico de Monterrey}

In 2013, Tecnologico de Monterrey declared its evolution to the TEC21 Educational Model to prepare students with comprehensive training that prepares them to face the challenges demanded by today's changing and uncertain world and ensure the international competitiveness of its graduates. The Tec21 Model aims to enhance the students' professional skills for generations to come, to be leaders who face the challenges and opportunities of the 21st century (ITESM, 2016).

This change brought with it a new curriculum structure and four types of curricular learning units delimited in content and time: Subjects, Blocks, Tec Weeks ("Semana i") and Tec Semester ("Semestre i"). Tec Week is a curricular space of total immersion in activities or experiences, on or off-campus, contributing primarily to the development of transversal competencies (ITESM, 2018).

In the context of Tec week, two different activities were designed to develop diversity competency: "Me, You, Others, Us" and "Diversity in a Globalized World" (see Table 1). These activities had a one-week duration and consisted of total immersion in which the experiences and activities aimed to guide students in life and career planning and prepare them for immersion into professional life.

Table 1: Design of the Tec Week activities

\begin{tabular}{llll}
\hline Activity & Participants & Objectives & Contents \\
\hline Me, You, & Students from the & - Reflect and become & - What is diversity? \\
Others, Us & undergraduate & aware of diversity and & - Discrimination and human \\
& programs of & human rights. & dignity \\
& Medicine, & - Understand and own the & - Your role within diversity- \\
& Odontology, & concepts of human & The 5Ds of human rights, \\
& Nutrition, & dignity, diversity, human & dignity, discrimination, \\
Biosciences and & rights in your community, & inequality, diversity \\
& Clinical Psychology & discrimination and & - Problem-solving strategies. \\
& & inequality. & - Actions in favor of \\
& & & diversity
\end{tabular}

\begin{tabular}{|c|c|c|c|}
\hline $\begin{array}{l}\text { Diversity in } \\
\text { a globalized } \\
\text { world }\end{array}$ & $\begin{array}{l}\text { Students from the } \\
\text { undergraduate } \\
\text { programs of } \\
\text { Medicine, } \\
\text { Odontology, } \\
\text { Nutrition, } \\
\text { Biosciences and } \\
\text { Clinical Psychology }\end{array}$ & $\begin{array}{l}\text { - Recognize diversity as } \\
\text { an enriching element for } \\
\text { the social context. } \\
\text { Generate effective } \\
\text { environments to facilitate } \\
\text { collaboration and } \\
\text { negotiation in } \\
\text { multicultural contexts and } \\
\text { solutions based on Human } \\
\text { Rights and peace-building } \\
\text { principles. }\end{array}$ & $\begin{array}{l}\text { - Gender perspective } \\
\text { - Human rights } \\
\text { - Human Rights in Mexico } \\
\text { - Human rights situation } \\
\text { - From my archetype to the } \\
\text { stereotype } \\
\text { - Worldviews } \\
\text { - Education for peace. }\end{array}$ \\
\hline
\end{tabular}




\section{Research Questions}

Table 1 illustrates the need to consider Tec Week as a training space for generic competencies, where students become aware of human rights and the diversity in the populations they will serve, not only during their Tec week activities but in the future. The research question arises:

How do Tec Week activities at a private educational institution in the city of Monterrey enable the development of diversity competency in students enrolled in the schools of Medicine, Dentistry, Biosciences, Nutrition and Clinical Psychology?

\section{Research Objectives}

For the research to be appropriately directed towards what is intended to be studied, it is necessary to consider the following objectives:

- Identify the development of diversity competency in the educational innovations designed to develop it.

- Establish whether the activities of Tec Week serve as a setting to develop diversity competency.

\section{Methods}

This quantitative study used a descriptive and cross sectional design to document the students' perception of their diversity competency development. The context was a private, non-profit Mexican university. Participants in the study answered a pre-test and post-test voluntarily. The instruments were applied to 21 first-semester students in the undergraduate programs of Medicine, Odontology, Nutrition, Biosciences, and Clinical Psychology who were enrolled in the Tec Week activities "Me, You, Others, Us" and "Diversity in a Globalized World."

The self-reflection questionnaire by Olivares et al. (2018) was used. This instrument was validated by focus groups and had a Cronbach's alpha of 0.97. It was sent online through Google Forms as a pretest and post-test to measure the perceived value by the students. The instrument used a Likert scale from 1 to 5 , where 1 was "totally agree," and 5 was "totally disagree." The pre-test measured the expectations and preferences of the students, and the post-test measured the achievements of the students in Tec Week according to the Confirmation Theory of Expectations (Olivares et al., 2019).

For the statistical analysis, the Wilcoxon test was used on the study's objective, type of sample, and variables and distribution, as recommended by Flores, Miranda \& Villasís (2017). It provided a global perspective of the questionnaire regarding the diversity competency in health professionals in four dimensions: ideologies, inclusion with vulnerable groups, couple and family models (LGBT), and gender equity. The program used to analyze the variables was Microsoft Excel 2013.

In this research, the students were informed that the purpose of the instrument was for educational research. All granted informed consent and collaborated voluntarily. The personal data of the participants were treated confidentially. 


\section{Results}

The students' pre and post-test self-reflection results presented in Table 2 show the achievement of their expectations regarding the diversity competency. Table 3 presents the dimensions in which students felt more and less confident about the diversity competency in the two Tec Week activities, Me, You, Others, Us, and Diversity in a Globalized World.

The quantitative nature of the self-reflection questionnaire allowed us to compare and do statistical analyses of the pre and post-test results. The self-reflection results on the diversity competency by the 21 health students identified that their expectations were fulfilled (Table 2) by the two Tec Week activities.

Table 2: Perceived value of diversity competency

\begin{tabular}{lllll}
\hline Skill & Mean pre-test & Mean post-test & P Value & Interpretation \\
\hline Diversity & 4.32 & 4.30 & 0.11 & Complies \\
\hline
\end{tabular}

The assessment focused on if the activity fulfilled their expectations to interact with classmates having ideologies different from theirs, if they participated in inclusion initiatives with vulnerable groups such as the elderly and people with disabilities, if they were in favor of diversity in couples and different family models, and if they supported gender equality (see Table 3).

Table 3: Self-reflection questionnaire: Dimensions of the diversity competency (Olivares, 2018)

\begin{tabular}{lllll}
\hline Dimension & $\begin{array}{l}\text { Mean pre- } \\
\text { test }\end{array}$ & $\begin{array}{l}\text { Mean } \\
\text { post-test }\end{array}$ & P Value & Interpretation \\
\hline $\begin{array}{l}\text { Living with colleagues with } \\
\text { different ideologies from } \\
\text { mine (religion, politics and } \\
\text { culture) }\end{array}$ & 4.29 & 4.38 & 0.15 & Complies \\
\hline $\begin{array}{l}\text { Participate in inclusion } \\
\text { initiatives with vulnerable } \\
\text { groups (older adults, people } \\
\text { with disabilities) }\end{array}$ & 3.43 & 3.95 & 0.16 & Complies \\
\hline $\begin{array}{l}\text { In favor of the diversity in } \\
\text { couples and family models } \\
\text { (LGBT) }\end{array}$ & 4.57 & 4.29 & 0.46 & Complies \\
\hline $\begin{array}{l}\text { Strengthen my support for } \\
\text { gender equality (salaries, } \\
\text { leadership positions) }\end{array}$ & 5 & 4.57 & 0.98 & Complies \\
\hline
\end{tabular}

One of the first findings was identifying the dimension in which students feel confident about their self-reflection regarding the diversity competency. That dimension was "Strengthen my support for gender equality" in both the pre-test and the post-test. However, the dimension in which they did not feel comfortable about the diversity competency was "Participate in Inclusion Initiatives with Vulnerable Groups," as shown in Figure 1 in the pre-test and post-test. 


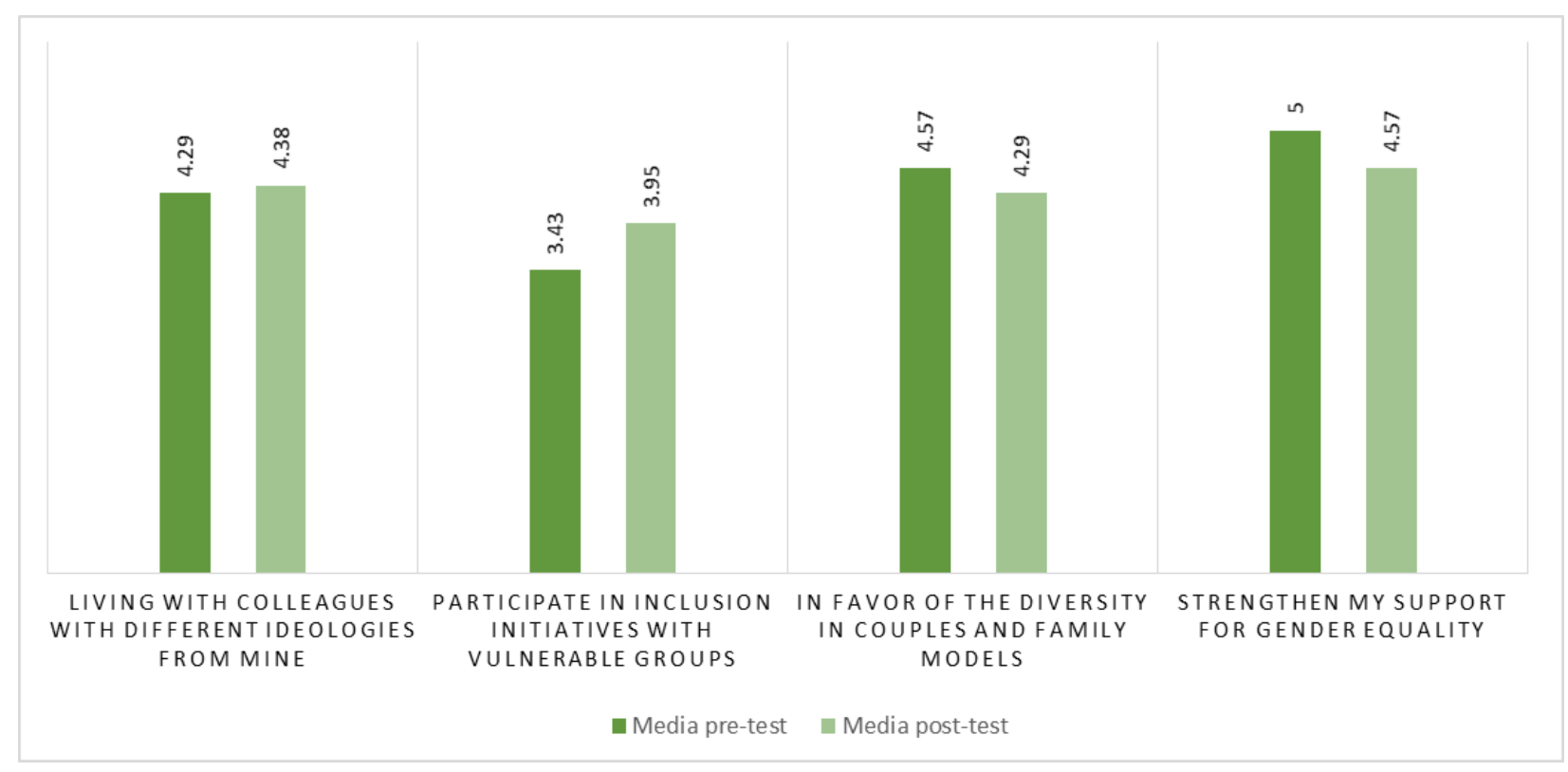

Figure 1 Means comparison of dimensions of the diversity competency during the Pre and Post-Test

The above shows the self-reflection experience results of the students in the health area regarding the diversity competency before and after participating in the two Tec Week activities, "Me, You, Others, Us," and "Diversity in a Globalized World." It displays data that could seem insignificant but presents the way students conceive and change their minds once they have been in situations that will confront them daily in their lives as future healthcare specialists.

\section{Discussion}

As in some previous studies, this study contributes to understanding the development of generic competencies. These competencies should be given the same priority as the hard disciplinary competencies of the profession since, according to employers, soft competencies such as teamwork, leadership, decision-making, resilience, acceptance of diversity, and ethical behavior are critical to professional life. It is essential to empathize and understand the patient and other professionals from a socio-cultural perspective (Pang et al., 2019).

This study provides a new vision of diversity competency and its relevance in training health professionals to establish targeted practices in new environments and courses and develop strategies that close the human gap between the health professional and the patients. In this sense, institutions that train health professionals must generate more learning environments and study units that promote transversal competencies, as occurred in this study during Tec Week. By doing so, students may experience learning that is genuinely transformative and impacts the immediate community. Upon graduation, students will be equipped to care for the needs of different populations. However, another need is for the curricula to consider the diversity of the students and teachers in the classrooms.

Diversity training guarantees that future healthcare professionals can respond to the various needs of diverse populations. Therefore, this study program focused on the students' total immersion in an experience where they could reflect and be aware of multiple human rights, diversity discrimination and inequality concepts, fulfilling the objectives of the Tec Week "Me, You, Others" curriculum. They will be able to recognize diversity as an enriching element of social contexts. This will allow them to 
collaborate and negotiate effectively, problem-solve, and consider human rights concepts within a multicultural environment, striving for peace agreements, all as established by the Tec Week "Diversity in a Globalized World" activity.

López (2016) states that students must learn to recognize and appropriately address gender and cultural prejudices when providing health care. Students must focus patient care on the individual since all healthcare professionals must be equipped and trained to respond to different individual needs within a diverse population.

The analysis of the results regarding the dimensions of diversity (ideologies, inclusion with vulnerable groups, couple and family models (LGBT), and gender equity) relates, in some points, to what was established by Seeleman (2015) in their study on the importance that health organizations attach to these transversal skills. That study did a comparative analysis of six different international approaches to healthcare in Europe, Australia and the USA. They all shared diversity in ethics, culture, linguistics, vulnerable groups, socioeconomic status and gender. While Seeleman (2015) focused on the organizations' and institutions' approach to dealing with diversity issues, this study focused on the diversity training of future healthcare professionals from the classroom to the clinical setting. We highlight the importance of previous training before coming into actual contact with real patients, ensuring that the students develop various communication and interactive skills using tools such as social media. The use of social media tools helps the students gain awareness of what is transpiring worldwide in real-time. They can observe the cultural dynamism that opens new doors and opportunities for healthcare professionals and allows them to apply their acquired skills when providing care while respecting human rights and diversity.

\section{Conclusion}

The development of diversity competency as part of the training of health professionals represents the opportunity to acquire transversal competencies such as empathy, humanism, ethics, and professionalism. A new generation of students is being nurtured who understand more than their patients' diseases. Their assessments consider their prejudices and their patients' diversity, including cultural, ethnic, social, and political characteristics.

The study results showed that the activities of Tec Week ("Me, You, Others, Us," and "Diversity in a Globalized World") promoted diversity competency in its four dimensions: ideologies, inclusion, family models (LGBT), and gender equity. The validated study shows that developing competency in diversity is paramount to improving the health professionals' performance and quality because it is an essential element of patient-centered care that considers socio-cultural aspects.

This study had some limitations, such as the small sample size and the focus on only one competency. However, the preceding does not limit the contribution of this work to understanding that diversity competency is relevant and of vital importance in the comprehensive training of health professionals. This competency is not the only priority, so to achieve it, the involvement of all stakeholders is necessary to keep it in view. Institutions must manage resources and develop the necessary training strategies, anticipating future challenges of diverse societies. 
Future studies should consider diversity competency and other probably misnamed "soft" skills, which enrich daily work, personal, and social activities. A professional who owns these skills manifests openness, interest, and disposition towards diversity. Respecting diversity as a key and enriching element of professional and personal endeavors leads to training professionals who provide patient-centered care focused on human rights and consider the wide variety of emerging cultures' characteristics.

\section{Acknowledgments}

The authors would like to acknowledge the technical support of Writing Lab, Institute for the Future of Education, Tecnologico de Monterrey, Mexico, in the production of this work.

\section{References}

Bundesamt für Justiz (2006). Allgemeine Gleichbehandlungsgesetz (AGG). Germany: Bundesamt für Justiz.

Crespí, P., \& García, J. (2020). Generic competencies in the University. Evaluation of a training program. Educación XX1, 24(1). doi: https://doi.org/10.5944/educxx1.26846

Flores, E., Miranda, M., \& Villasís, M. (2017). The research protocol VI: How to choose the appropriate statistical test. Inferential statistics. Revista Alergia México, 64(3), 364-370. doi: https://doi.org/10.29262/ram.v64i3.304

INEGI. (2017). National Survey on Discrimination. Mexico: INEGI.

INEGI. (2020). Tell me about Mexico. Retrieved from Tell me about Mexico Web Site: http://www.cuentame.inegi.org.mx/poblacion/discapacidad.aspx?tema=P

ITESM. (2016). Tec21 Educational Model. Mexico: Tecnologico de Monterrey.

ITESM. (2018). Tec Week Guidelines. Mexico: Tecnologico de Monterrey.

López, L. (2016). Cultural competency, a key for better health outcomes. MedUNAB, 18(3), 163-165. doi: https://doi.org/10.29375/01237047.2569

Morales, J.C. (2009). Comprehensive training and medical professionalism: a proposal for work in the classroom. Educación Médica, 12(2), 73-82.

Olivares, S. L. (2015). Business Graduate Skills: Competency-Based Model. En M. A. Khan, Diverse Contemporary Issues Facing Business Management Education (p. 25-51). Hershey, PA: IGI Global.

Olivares, S., Torres, E., Avila, E., Turrubiates, M., López, M. \& Valdez, E. (2018). Perceived value from immersion educational experience for the development of transversal competences: i Week. Educación Médican, 20(2), 93-99. doi: https://doi.org/10.1016/j.edumed.2018.04.015

Olivares, S., Adame, E., Treviño, J., López, M., \& Turrubiates, M. (2019). Action learning: challenges that impact employability skills, Higher Education, Skills and Work-Based Learning, 10(1), 203-216. doi: https://doi.org/10.1108/HESWBL-07-2019-0097

Pang, E., Wong, M., Leung, C. H., \& Coombes, J. (2019). Competencies for fresh graduates' success at work: Perspectives of employers. Industry and Higher Education, 33(1), 55-65. doi: https://doi.org/10.1177/0950422218792333

Pugh, G, \& Lozano, A. (2019). Development of generic skills in post-secondary vocational education: a case study. Calidad en la educación, (50), 143-170. doi: https://dx.doi.org/10.31619/caledu.n50.725

Salgado, F., Corrales, J., Muñoz, L., \& Delgado, J. (2012). Design of course programs based on competencies and their application at the Universidad del Bío-Bío, Chile. Revista chilena de ingeniería, 20(2), 267-278. doi: http://dx.doi.org/10.4067/S0718-33052012000200013 
Seeleman C, Essink, M., Stronks K, \& Ingleby, D. (2015). How should health service organizations respond to diversity? A content analysis of six approaches. BMC health services research, 15, 510. doi: https://doi.org/10.1186/s12913-015-1159-7

Sias, J., Loya, A., Rivera, J., \& Shenberger, J. (2017). Cultural Competency. In J. DiPiro, R. Talbert, G. Yee, G. Matzke, B. Wells, \& L. M. Posey, Pharmacotherapy: A Pathophysiologic Approach. McGraw Hill.

Shaya, F. T., \& Gbarayor, C. M. (2006). The case for cultural competency in health professions education. American journal of pharmaceutical education, 70(6), 124. doi: https://doi.org/10.5688/aj7006124

Suarez, Y., Balcazar, F., García, M., \& Taylor, T. (2019). Ecological theory and research in multicultural psychology: a community psychology perspective. In F. T. L. Leong, L. Comas-Díaz, G. C. Nagayama Hall, V. C. McLoyd, \& J. E. Trimble (Eds.) APA handbook of multicultural psychology, Vol. 1. Theory and research (p. 535-552). American Psychological Association. https://doi.org/10.1037/14189-029

Sweetman, C. (2004). Gender, Development, and Diversity. Oxfam.

NU. (2017, Marzo 2). The Defender of Migrants. Mexico, Ciudad de Mexico.

Vinasco, I. C. A. (2018). School environments: spaces for recognition and respect for diversity. Sophia, 14(2), 84-93. doi: https://doi.org/10.18634/sophiaj.14v.2i.85 